\title{
Performance evaluation of WWW conference system for supporting remote mental healthcare education
}

\author{
Kaoru Sugita* \\ Department of Information and Communication Engineering, \\ Fukuoka Institute of Technology (FIT), \\ 3-30-1 Wajiro-Higashi, Higashi-Ku, \\ Fukuoka 811-0295, Japan \\ E-mail: sugita@fit.ac.jp \\ ${ }^{*}$ Corresponding author
}

\section{Noriki Uchida}

Global Software Corporation, Japan

E-mail: uchida@globals.jp

\section{Giuseppe de Marco}

Toyota Technological Institute,

Tenpaku-Hisakata, 1-12-1 Nagoya 468-8511, Japan

E-mail: demarco@toyota-ti.ac.jp

\section{Leonard Barolli}

Department of Information and Communication Engineering, Fukuoka Institute of Technology (FIT), 3-30-1 Wajiro-Higashi, Higashi-Ku

Fukuoka 811-0295, Japan

E-mail: barolli@fit.ac.jp

\section{Arjan Durresi}

Department of Computer and Information Science, Indiana University Purdue University Indianapolis, Indianapolis, IN 46202, USA

E-mail: durresi@cs.iupui.edu

\begin{abstract}
In order to decrease the moving time of mental healthcare specialists, we have developed a WWW conference system, which can provide the communication between mental healthcare specialists and their students. We implemented the prototype system in LAN environment and analysed the performance by changing the frame rate, frame size and number of clients. The experimental results show that system has enough performance in the LAN environment but PCs need a high CPU power to send, receive and display the high quality live videos.
\end{abstract}


Keywords: WWW based system; mental healthcare education; flash; flash communication server.

Reference to this paper should be made as follows: Sugita, K., Uchida, N., de Marco, G., Barolli, L. and Durresi, A. (2008) 'Performance evaluation of WWW conference system for supporting remote mental healthcare education', Int. J. Virtual Technology and Multimedia, Vol. 1, No. 1, pp.75-93.

Biographical notes: Kaoru Sugita is an Associate Professor in Department of Information and Communication Engineering, Fukuoka Institute of Technology, Japan. He received BE, MS and PhD Degrees from Saitama Institute of Technology, Toyo University and Iwate Prefectural University in 1998, 1999 and 2003, respectively. From April 1998 to November 2002, he was working for ATA Corporation. From April 2003 to March 2004, he was a Post Doctor Researcher at Iwate Prefectural University. From September 2003 to March 2004, he was working with NetBridge Company. His research interests include multimedia communication systems. He is member of IPSJ and IEICE.

Noriki Uchida is System Engineer at Global Software Coorporation, Japan. He recieved BS of Chemistry and Phychology from University of Tennessee in 1994, and MS of Software and Information Science from Iwate Prefectural University in 2003. He has worked at NetBridge Inc, from 2001 to 2005 , and Global Software Corporation from 2005. His research interests include wireless networks, multimedia transmission systems, and disaster information systems.

Giuseppe de Marco received the Degree ('laurea') in Electrical Engineering in 1999 from University of Bologna, Italy. He received $\mathrm{PhD}$ from University of Salerno, Italy, in 2004. From 2004, he was a Research Fellow at University of Salerno, and a postdoc researcher at Fukuoka Institute of Technology, Japan, under a scholarship from Japan Society for the Promotion of Science (JSPS). Presently, he is a postdoc researcher at Toyota Technological Institute, Japan. His research interests are: network protocols, performance evaluation of wireless systems, inter-vehicle communication, sensor networks, and multimedia applications. He is member of IEEE.

Leonard Barolli is a Professor at Department of Information and Communication Engineering, Fukuoka Institute of Technology (FIT), Japan. He has published more than 200 papers in refereed journals and international conference proceedings. He has served as a Guest Editor for many journals. He was PC Chair of IEEE AINA-2004 and ICPADS-2005. At present, he is Workshops Chair of iiWAS/MoMM-2007 and General Co-Chair of IEEE AINA-2008. His research interests include high-speed networks, P2P, ad-hoc networks, sensor networks, and multimedia systems. He is a member of IEEE, IPSJ and SOFT.

Arjan Durresi is an Associate Professor of Computer Science at Indiana University Purdue University Indianapolis. His current research interests include network architectures, heterogeneous wireless networks, security, QoS routing protocols, traffic management, optical and satellite networks, performance testing, multimedia systems, and bioinformatics. He has authored more than 50 papers in journals and more than 80 in conference proceedings. $\mathrm{He}$ is on the editorial boards of Ad Hoc Networks Journal (Elsevier) and Journal of Ubiquitous Computing and Intelligence. 


\section{Introduction}

Recently in Japan, the mental healthcare has become a very important issue because there are many people suffering from mental problems. Also, there are only few specialists and researchers to deal with these problems. For example, bullying at school is one of the big problems worrying teachers in Japan today. Also, there are other problems such as refusal to go to school and the school violence. However, there are few counsellors in Japanese schools. It should be noted that many of these specialists are also doing other works. In general, one mental healthcare specialist should take care for many patients and they want to see their face. They should take up not only the counselling but also the individual aftercare.

The Information Technology (IT) has changed our life. People can communicate between them, and students can study various courses anywhere and at anytime using the internet. The IT can be helpful for mental healthcare, education, aftercare and counselling for patients and their families. Because there are very few mental healthcare specialists, it is very important to decrease their moving time. Also, it is very important to see the facial expression and talk to people for mental healthcare education, aftercare and counselling. For this reason, the video and voice are needed.

Recently, because of the use of ADSL and FTTH (NTT West, 2004), many people can use several Mbps on the internet. So, many people can use the live video streaming and TV conference. For example, the live video streaming is used for the tourist attractions broadcasting (Kumamoto-shi, 2001; Fuji-shi, 2005; Sapporo-shi, 2004), assembly broadcasting (The House of Representatives, 1999; The House of Councilors, 2005), public information broadcasting (The Ministry of Public Management, 2004). In these live video streaming methods, the image refreshed at regular intervals over WWW (Kumamoto-shi, 2001; Fuji-shi, 2005; Sapporo-shi, 2004) and RealPlayer or Windows Media Player (The House of Representatives, 1999; The House of Councilors, 2005; The Ministry of Public Management, 2004) are used.

In some TV conference systems are used special hardware (Polycom, 2004; vtel, 2004; Sony, 2004; NEC Engineering, 1996) and in other systems are used application software or PC connected to the existing cameras (Microsoft, 2004; Visual Nexus, 2004; Advanced Solutions, 2001, 2002; Hitachi Hybrid Network, 2004). When using the special hardware, the users need to connect to the internet and set up the hardware in each spot before using the system. But, it is difficult to use the special hardware in counselling because the users are usual people. While, when using the application software and PC connected to the existing camera, the users need to connect the PC and camera, set up the PC and install the application software in each spot before using the system. Also, it is difficult to introduce these systems for mental healthcare because the mental healthcare specialists and their students are not computer specialists.

To realise a remote mental healthcare education, we have developed a WWW conference system (Sugita et al., 2005). Our system is able to support the communication between the mental healthcare specialists and their students. Also, our system can provide the communication between the mental healthcare specialists, patients and their families by using the live video on WWW browser, point-to-point communication, point-to-multi-point communication and multi-point-to-multi-point communication. 
The organisation of this paper is as follows. In Section 2, we will introduce the related works. Next, we describe the WWW conference system and explain system architecture. The conference types are treated in the following section. After that, we show the connection management for each conference type and the flow of WWW conference system. Then, we show implementation of our proposed system by using Macromedia Flash and Macromedia Flash Communication Server and provide the experimental results. Finally, we give some conclusions and future works.

\section{Related works}

Existing communication systems are usually realised on the LAN environment and leased lines. Many remote education systems are proposed in Mori et al. (1992), Inoue et al. (1997), Wakahara (1998) and Sakiyama (2001). In Inoue et al. (1997) and Wakahara (1998), the multi-point-to-multi-point communication is used. While in Sakiyama et al. (2001), a video stream selection according to lecture context is proposed. In these systems, the remote users can communicate between them using the live video.

Recently, the live video communication systems have become very popular and the network speed is increased very fast. Therefore, the video-conference systems can be applied in the medical field. There are many video conference systems such as the medical tele-consultation support system using super high definition imaging system (Yamaguchi et al., 2001), remote medical support system using the transcoding function (Kawamura et al., 2003) and care communications service between hospitalised patients and their families (Abiko et al., 2003). In these studies, the system was implemented only for intranet or leased lines.

Some other communication systems using live video for remote learning systems (Maeda et al., 1997; Miyoshi et al., 2000) and for streaming video systems (Kato et al., 2003) has been proposed. In the multimedia communication environment for distance learning proposed in Maeda et al. (1997) are given the experimental results for remote learning using intranet and internet environments. In this study is shown that an efficient remote learning can be achieved by using $600 \mathrm{Kbps}$ bandwidth. Now, internet users can have more bandwidth by using ADSL and FTTH. And the live video over the internet is possible. In Kato et al. (2003), the authors propose a streaming video system for best-effort networks using adaptive QoS control rules to improve the satisfaction of streaming video services.

However, these systems cannot be used by usual people and they need special hardware and software. These systems use point-to-point communication, so they cannot be used for multi-point-to-multi-point communication. To overcome these problems, we have developed the WWW conference system, which uses multi-point-to-multi-point communication and can transmit live video over the internet.

\section{Proposed WWW conference system}

The proposed WWW conference system is shown in Figure 1. If the user has a video camera and $\mathrm{PC}$ connected to the internet, the user can communicate to the remote users by using live vide on WWW. Using our system, the user does not need to install and set 
up the application software. He just only needs to access the WWW conference server by using the WWW browser.

Figure 1 WWW conference

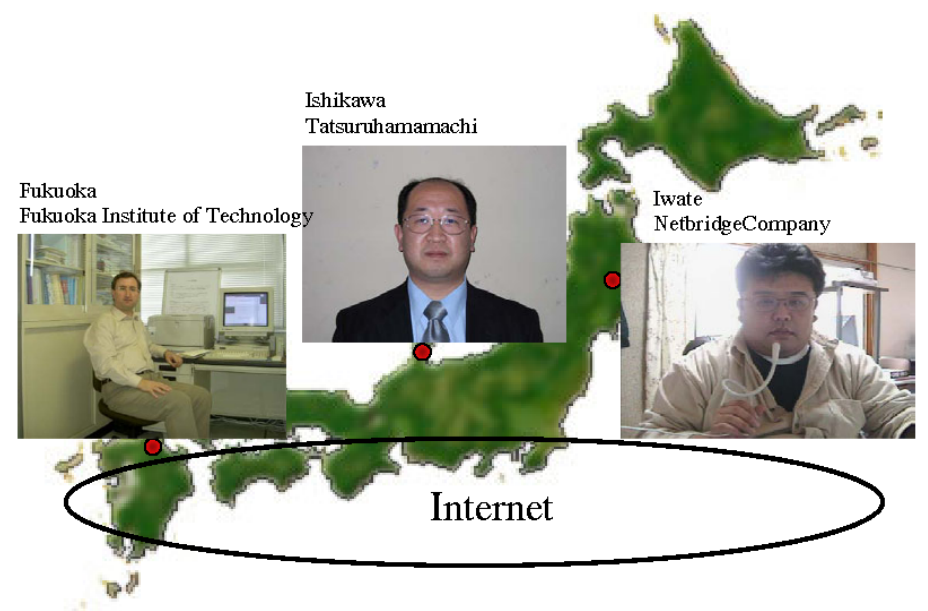

The concept of WWW conference is shown in Figure 2. The user can use various cameras such as the WWW camera, digital video camera and robot camera. But the camera should be identified and connected to the PC. Our system is composed of the WWW conference client and the WWW conference server. When the user accesses the WWW conference server by using a WWW browser, the WWW conference client is downloaded to the PC. After downloading the WWW conference, client provides the following functions:

- $\quad$ user authentication

- live video function

- video record function

- $\quad$ quality setting function.

Figure 2 WWW conference system

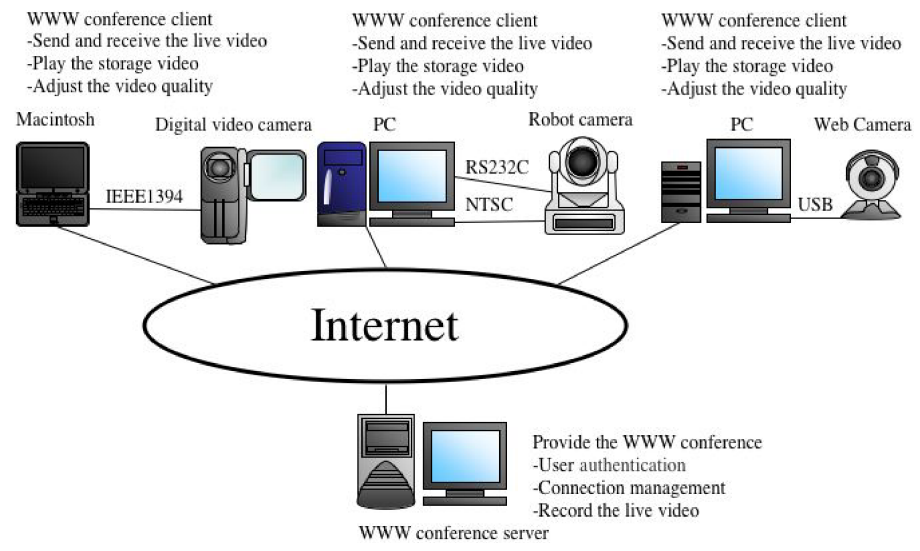


The user authentication function is provided by user ID and password. When the user logins to the WWW conference server, the user inputs its user ID and password. The user ID and password are compared with the registered ones in the WWW conference server. When the user ID and password do not match, the user fails to login and needs to input again its user ID and password. It should be noted that the user may fail to login when in the WWW conference server have already logined the maximum number of users.

The live video function provides the video data and voice data. The video data and voice data are sent and received by the video stream. They are encoded by H.263. Our system provides three types of conference using this function. To realise the live video, the WWW conference client has the connection management function, the video encode function and the video decode function. The WWW conference server has the connection management function.

The video record function records the live video stream and plays the recorded video stream on the WWW conference server. The user can record the live video stream and play the recorded video stream by using the WWW conference client. The recorded video stream is stored in the WWW conference server. The recorded video stream is used for learning the existing cases of counselling and replaying the instructions for mental healthcare.

The quality setting function modifies the video quality for local WWW conference client and remote WWW conference client. The local WWW conference client can modify the video size and frame rate. But, the remote WWW conference client can modify only the frame rate. When the PC does not have enough CPU power or network bandwidth, the voice data has delay and video data has frame loss and frame delay. However, our system can guarantee the quality of service such as "Frame rate is high and video size is small" and "Frame rate is low and video size is large" when the user modifies the video quality using this function.

\section{System architecture}

To implement our system, we propose a system architecture, which is organised by the WWW conference client and the WWW conference server as shown in Figure 3.

Figure 3 System architecture

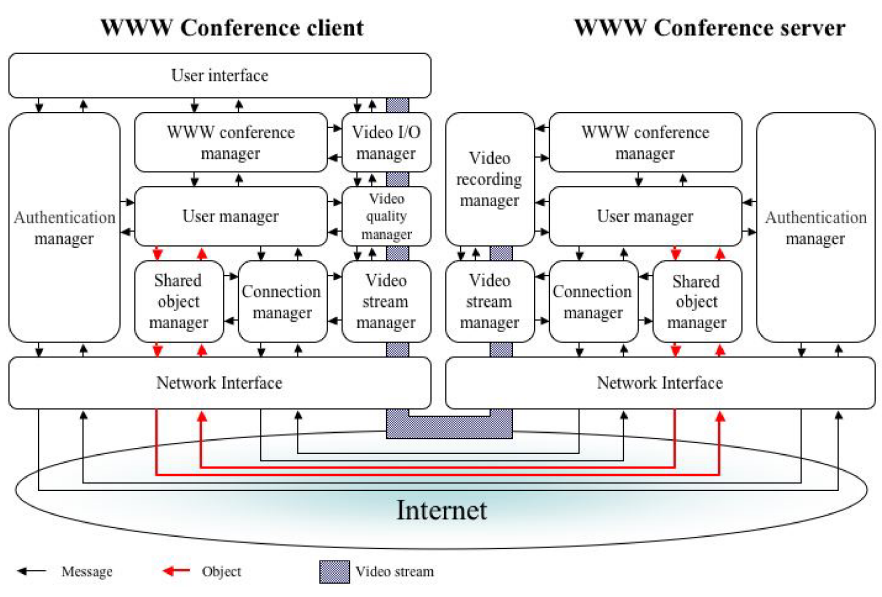




\subsection{WWW conference client}

Presently, there exist various network environments such as broadband network and narrowband network to connect to the internet. The bandwidth varies from $10 \mathrm{Kbps}$ to $100 \mathrm{Mbps}$. To realise the communication between various network environments, the WWW conference client is organised by User Interface (UI), Authentication Manager (AM), User Manager (UM), WWW Conference Manager (WCM), Connection Manager (CM), Shared Object Manager (SOM), Video I/O Manager (VI/OM), Video Quality Manager (VQM) and Video Stream Manager (VSM).

The UI provides the following functions:

- $\quad$ insertion of user ID and password

- $\quad$ set-up of video input and output device

- display of live video

- modification of video quality.

The AM authenticates the user ID and password by using the registered user ID and password on the WWW conference server. When the AM fails the authentication, the AM requests the user ID and password to the user again. When the AM succeeds the authentication, the AM sends the user ID to the UM. The UM manages the system users, the video quality for each video stream and the name of the recorded video stream. When maximum number of users have been logined to the WWW conference server, the UM rejects other users. The WCM sets up the number of maximum users and provides the user interface. The maximum number of users and the UI are decided by the conference type. The CM manages the connections of the other WWW conference clients, participating in the WWW conference. The CM converts the number of maximum users to the number of maximum connections. The SOM gets the shared object from the WWW conference server. The recorded video stream is played by using the video name. We use the shared object to record the name of video stream on the WWW conference server. When the user wants to record the live video stream through the UI, the SOM adds the name of video stream as the shared object to the WWW conference server. The VI/OM inputs the video data and sound data from the camera and the video stream is selected by the WCM. The VI/OM displays the video data and sound data from the video stream and the camera. Also, the VI/OM sends the video data and sound data to the VQM. The VQM decides the frame rate and the size of video by using the identified video quality. The VSM sends and receives the video data and voice data as the video stream to the WWW conference server. The other WWW conference clients operate in the same way.

\subsection{WWW conference server}

To realise the WWW conference and record the live video stream, it is needed to manage the video stream, including live video stream and recorded video stream. So, the WWW conference server is organised by the AM, WCM, UM, CM, SOM, Video Record Manager (VRM) and VSM. The AM manages the user ID and password. It compares the user ID and password with the registered user ID and password when the AM requests the authentication from the WWW conference client. The UM 
manages the users inside the system, the video quality for each video stream and the name of the recorded video stream. The WCM manages the user and video stream based on the type of conference. The CM manages the connection of the WWW conference clients. Then, it decides the number of maximum connections by using the number of maximum users. When the WWW conference server has already the maximum number of users, the CM rejects the new connection. The SOM stores the shared object, which is the name of video stream on the WWW conference server. The shared object remains even after disconnecting the WWW conference client. The VRM records and manages the video stream on the WWW conference server. The VSM manages the video stream between the WWW conference clients and the WWW conference server.

\section{Connection management}

For the remote mental healthcare education are needed various conference types. We introduce three conference types such as the point-to-point conference, multi-user conference and broadcast conference.

To provide the live video for distributed users, the video data and voice data are transmitted in the video streams. The number of video streams is decided based on the type of conference and the number of users. The WWW conference client can be connected to the remote WWW conference client via WWW conference server to create the video stream. Our system uses the channel to create and manage the video stream. Each channel has a channel number. The channel number is used for the clients' connection and selection of the video stream. In the point-to-point conference and multi-user conference, the channel numbers are assigned based on the connection order. While, in the broadcast conference, the channel numbers are selected by the user.

In Figure 4 is shown an example of the relation between the video stream and channel number in the point-to-point conference. This conference uses two video streams in each WWW conference client. One is used for the sender client and another for the receiver client. The sender video stream and receiver video stream have different channel numbers. After allocating the channel number, the WWW conference client creates the video streams by using the channel number.

Figure 4 Connection management for point-to-point conference

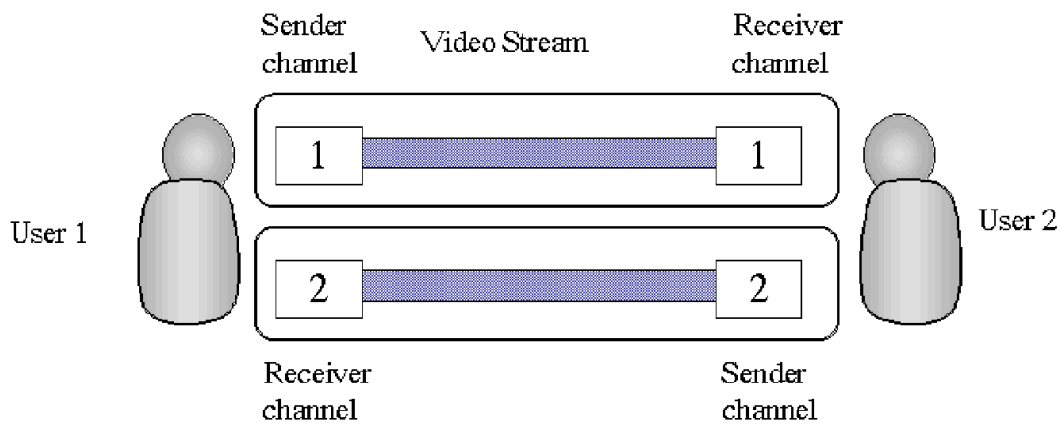


In this example, user 1 is connected to the WWW conference server before user 2 . For this reason, the channel number starts from 1 . The channels 1 and 2 are shown in Figure 4. In channel 1, user 1 is the sender and user 2 is the receiver of the video stream. While, in channel 2, user 2 is the sender and user 1 is receiver.

In Figure 5 is shown an example of the relation between the video stream and channel number in the multi-user conference. In this type, each user has its own video stream. The channel number is assigned the same as type one. After allocating the channel number, the WWW conference client creates the video stream for each receiver.

Figure 5 Connection management for multi-user conference

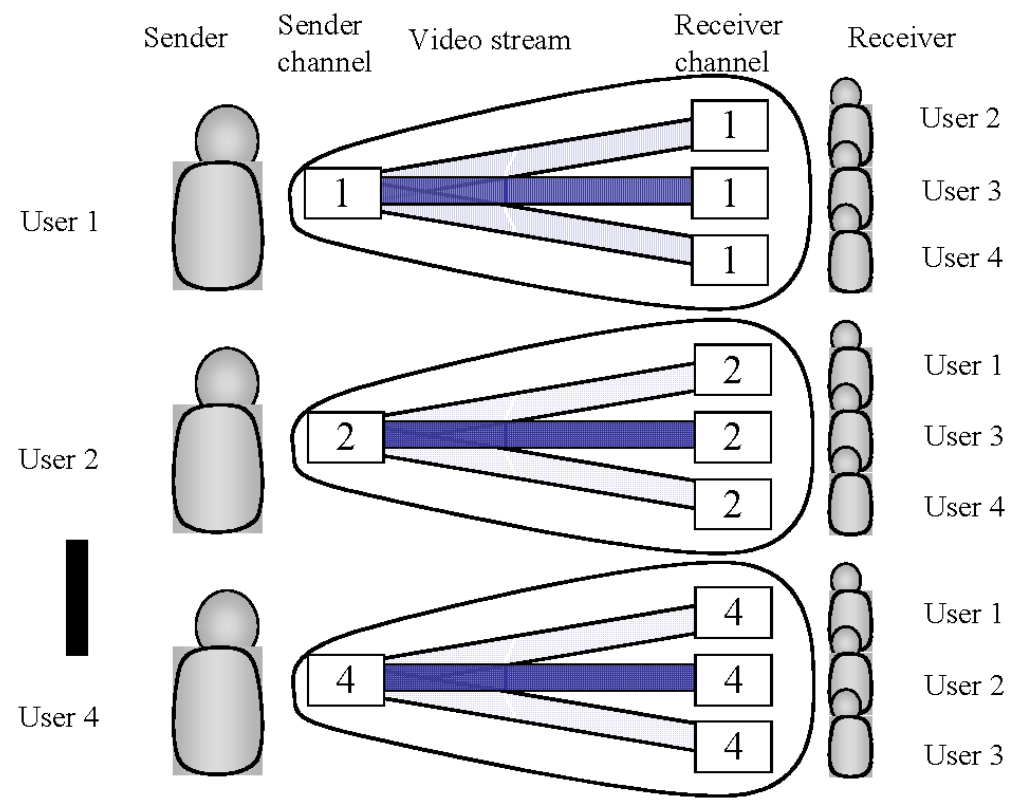

In this example, four users are connected to WWW conference server. In channel 1, user 1 is the sender and users 2, 3 and 4 are receivers. Each WWW conference client creates the video streams by using these channel numbers.

In Figure 6 is shown an example of the relation between the video stream and channel number in the broadcast conference. The user can select the sender channel number using the sender client. Then, the video stream is created based on the selected channel number. Also, the user can select the receiver channel number using the receiver client. It should be noted that a user cannot send the video stream in a channel when this channel is used by another user. But, the receivers can get the same channel at the same time. When the sender channel number has already been used, the WWW conference client displays this message: "This channel number has already been used". 
Figure 6 Connection management for broadcast conference

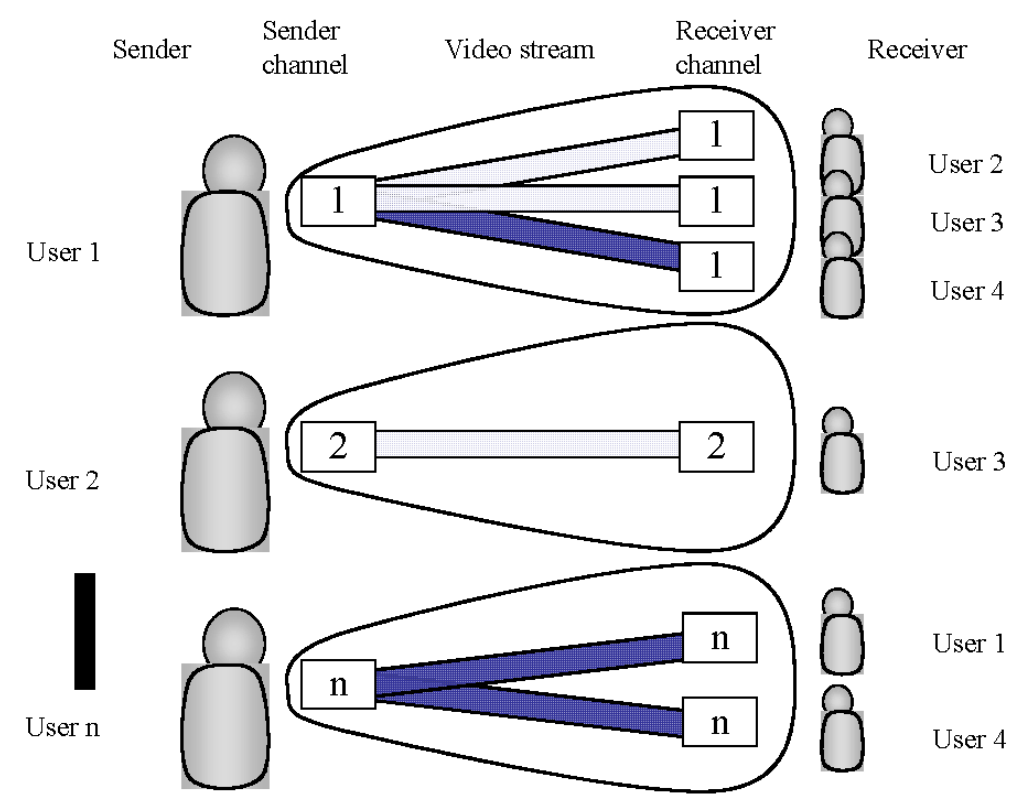

\section{WWW conference operation}

The WWW conference operation has two phases: the start-up phase and live video communication phase. In the start-up phase, the WWW conference client is downloaded and the user logins to the WWW conference server using the WWW browser. The live video communication phase consists of camera set-up, video quality modification, and sending and receiving the live video.

In Figure 7 is shown the start-up phase. First, the user downloads the desired type of the WWW conference client from the WWW conference server. After that, the WWW conference client starts up automatically and requires the user ID and password. When the user inputs the user ID and password, the WWW conference client sends this information to the WWW conference server to authenticate the user. When the authentication fails, the WWW conference client requests the user ID and password again. When the authentication succeeds, the WWW conference client creates the video streams. Then, the WWW conference client connects to the shared object to share the name of recorded video stream with other WWW conference clients.

In Figure 8 is shown the live video communication phase. First, the WWW conference client asks the user for the permission to use the camera. Next, the WWW conference client allocates the channel number to send and receive the live video stream. When the WWW conference client finishes the channel allocation, it starts to send/receive the live video streams to/from other clients via WWW conference server. When the user requests to record the live video stream, the WWW conference client sends this request to the WWW conference server. 
Figure 7 Start-up phase

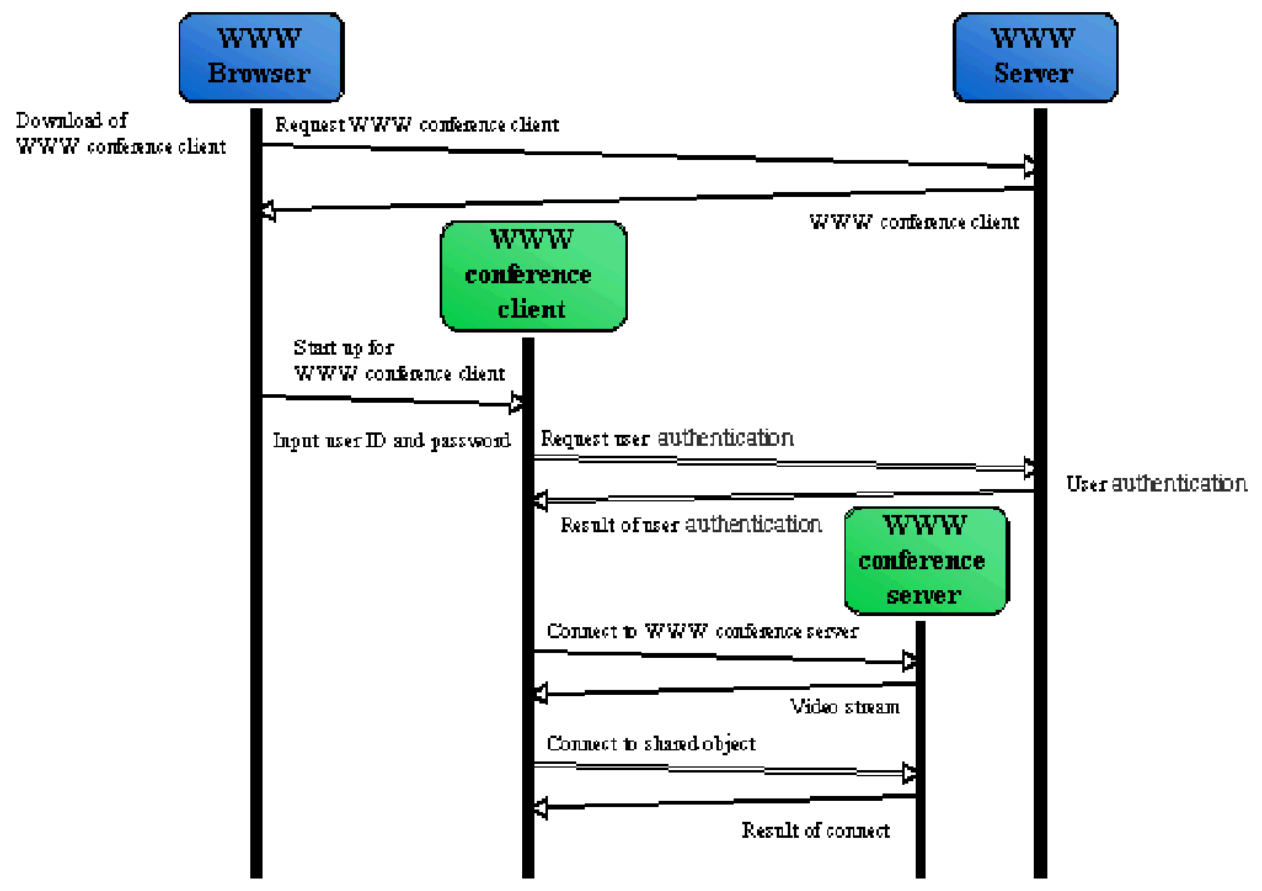

Figure 8 Live video communication phase

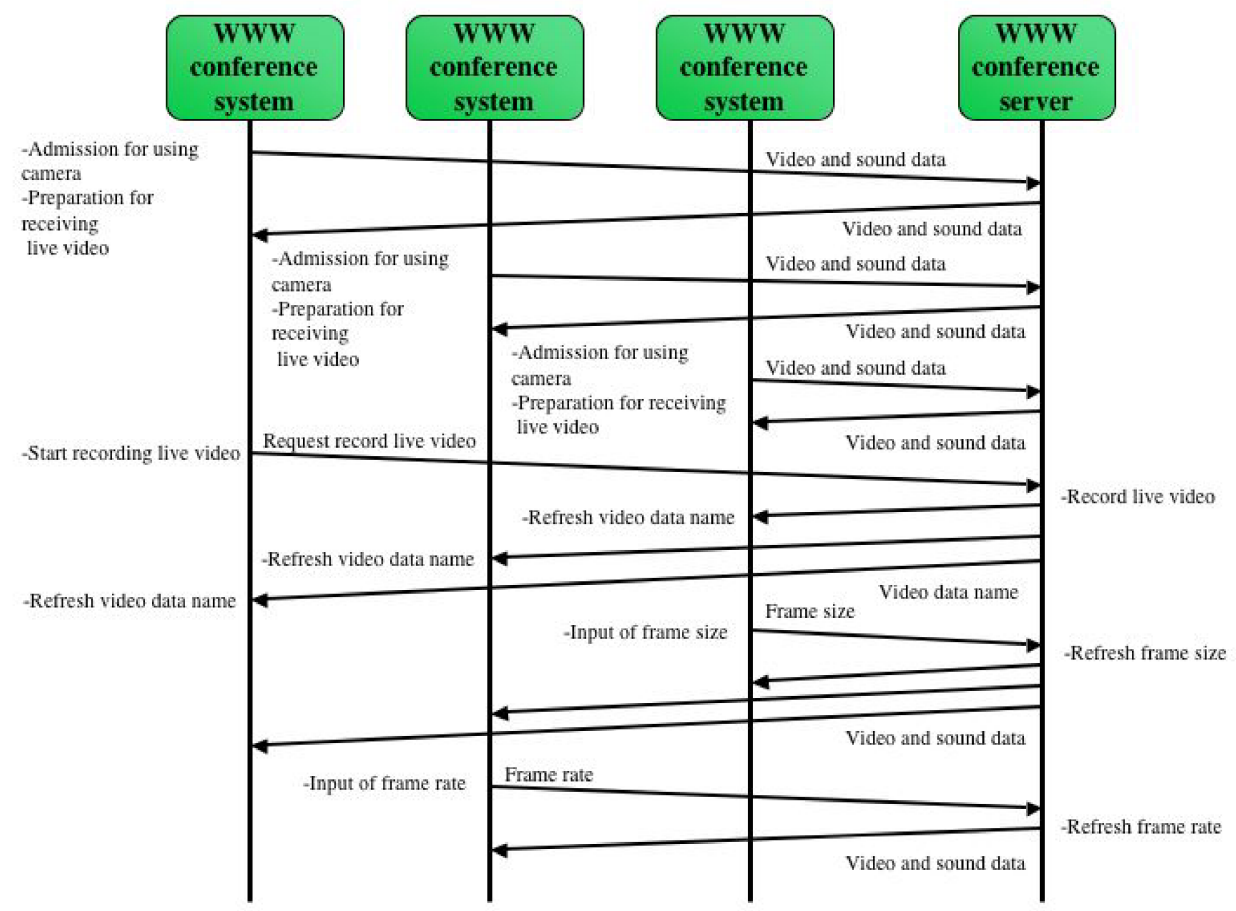


The WWW conference server adds the new name of live video stream to the shared object. Then, the name of live video stream is added to the connected WWW conference clients. When the user inputs the frame size, the WWW conference client updates the frame size, modifies the captured frame size and sends the modified frame size to the WWW conference server. When the WWW conference server receives the modified frame size, it updates the new frame size and sends the live video stream to the WWW conference clients using the new frame size. Also, the frame rate is updated the same as the frame size.

\section{Implementation}

In Figure 9 is shown the implemented system structure. The WWW conference client is implemented by using the Macromedia Flash Studio MX1.5 (Macromedia, 2004). The WWW conference server is realised by using the Apache1.3.29 and the Macromedia Flash Communication Server MX1.5 (Macromedia, 2003). The Apache1.3.29 is used to provide the WWW conference client to the users. The Macromedia Flash Communication Server MX1.5 is used for sending and receiving the video data and voice data. The live video streams are encoded by H.263. We implemented three types of applications for each type of conference. When the user downloads the desired type of application, the WWW conference client displays the authentication interface. The user can take part in the WWW conference after authentication.

Figure 9 Implemented system structure

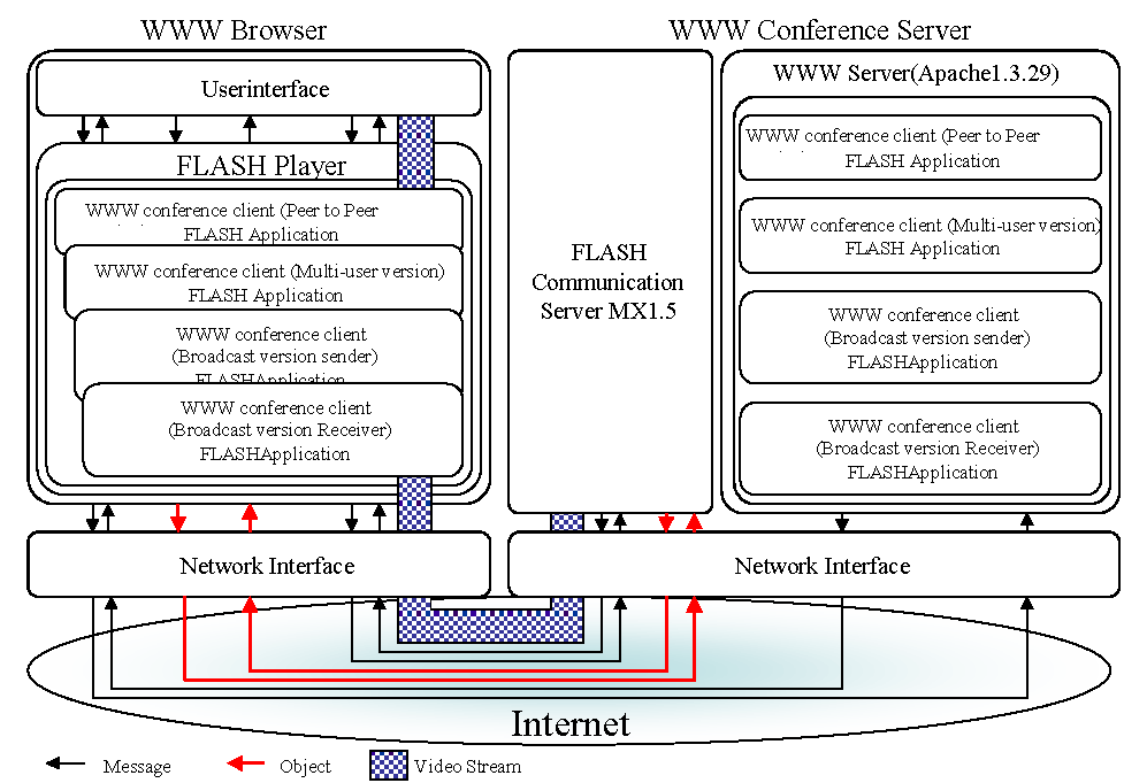

In Figure 10 is shown the example of our implemented system. The bottom side of interface shows the remote live video, recorded live video and local live video from the left to the right side. The list box and play button are shown below the recorded video. The list box is used to select the name of video stream and play button is used to play the 
recorded live video stream. The stop button is shown in the left side below the local live video stream. This button is used to stop the recorded live video stream. The record button is shown in the right side below the local live video. The user can record and play the live video stream by using these buttons. The main video display can be selected by clicking one of the videos shown in the bottom side. The video quality set-up is shown in the upper side of the interface. The interface also has in the bottom sides some list boxes, which are used to change the frame size and frame rate. The frame size can be changed only at the local live video.

We evaluated the performance of our system on the LAN environment (100 Mbps) as shown in Figure 11. We analysed the throughput and load average for the multi user conference. In this experiment, six PCs and one projector were used. The screen and projector are used for playing video data. The live video is captured by taking the screen in each WWW conference client. In Table 1 are shown PCs characteristics. Four note-book PCs are used as WWW conference clients. PC A is used as video projector and $\mathrm{PC} \mathrm{B}$ is used as WWW conference server.

Figure 10 Point-to-point conference application

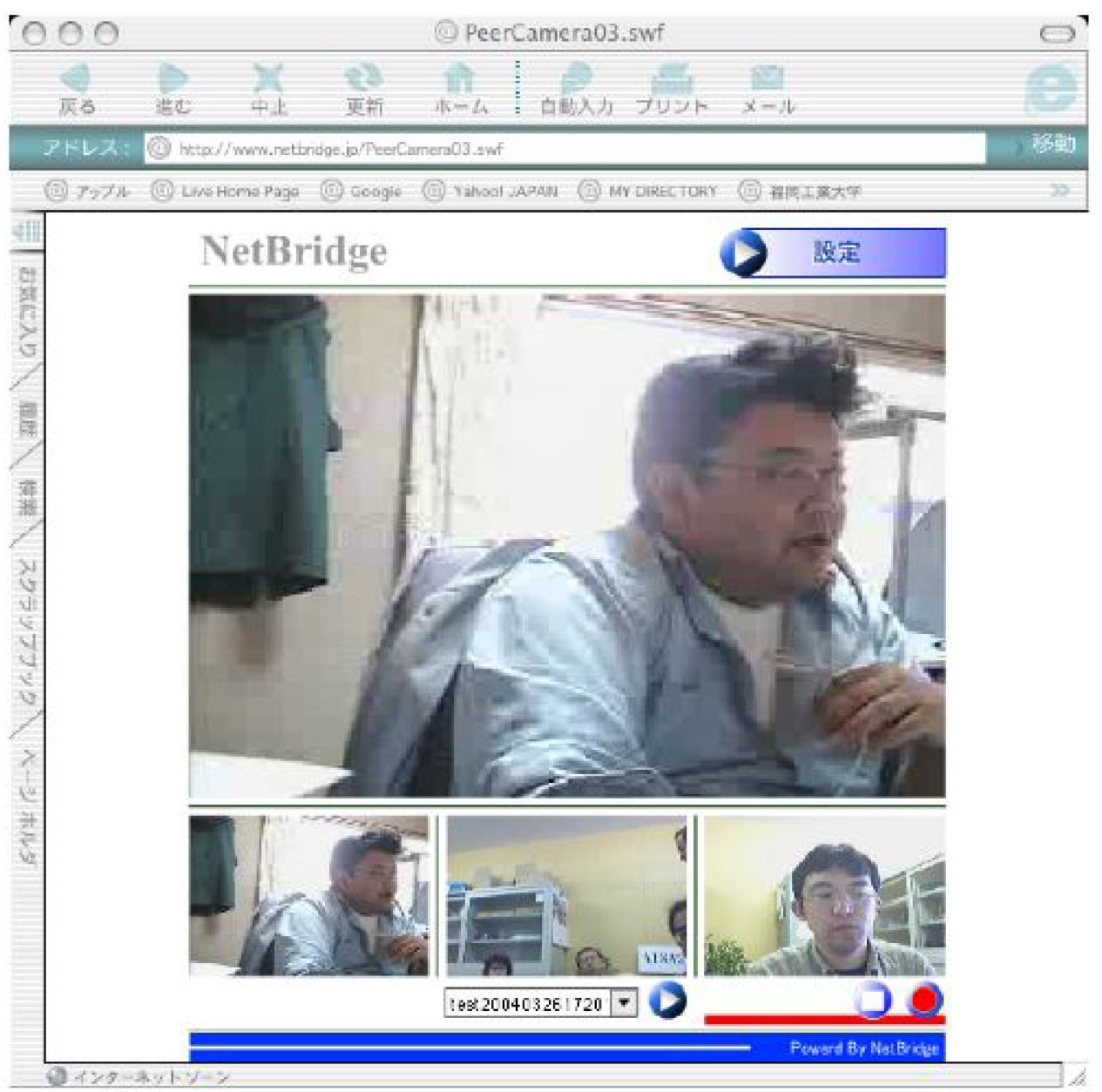


Table 1 PCs characteristics

\begin{tabular}{lllcc}
\hline Type of PC & Purpose & CPU $(\mathrm{Hz})$ & Memory $(\mathrm{MB})$ & OS \\
\hline NPC 1 & WWW conference client & PentiumM $(1.1 \mathrm{GHz})$ & 256 & Windows XP \\
NPC 2 & WWW conference client & PentiumM $(1.1 \mathrm{GHz})$ & 256 & Windows XP \\
NPC 3 & WWW conference client & PentiumM $(1.1 \mathrm{GHz})$ & 256 & Windows XP \\
NPC 4 & WWW conference client & Celeron $(700 \mathrm{MHz})$ & 192 & Windows XP \\
PC A & Video projection & PowerPC G5 $(1.8 \mathrm{GHz}) \times 2$ & 256 & MacOS X10.3 \\
PC B & WWW conference server & Pentum4 $(2.6 \mathrm{GHz})$ & 1024 & Windows XP \\
\hline
\end{tabular}

Figure 11 Prototype environment for evaluation

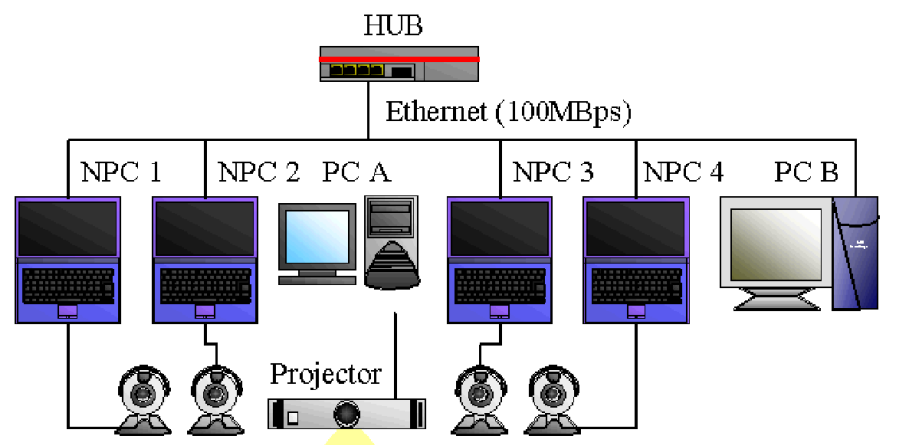

\section{Screen}

In Figures 12 and 13 are shown the relation between the frame rate and throughput at WWW conference client and Figure 14 shows the relation between the frame rate and average load. In this experiment, we use $352 \times 264$ pixels as frame size. We see that the load average and throughput are affected by the frame rate at client side. Also, the average load and throughput are different for different number of clients. But we found that the amount of sent data does not change more than $26 \mathrm{fps}$. This is because the PCs do not have enough CPU power and the average load is close to $100 \%$. After that, the throughput remains the same. In such a case, the frame is delayed and the average load becomes high. 
Figure 12 Relation between frame rate and amount of received data

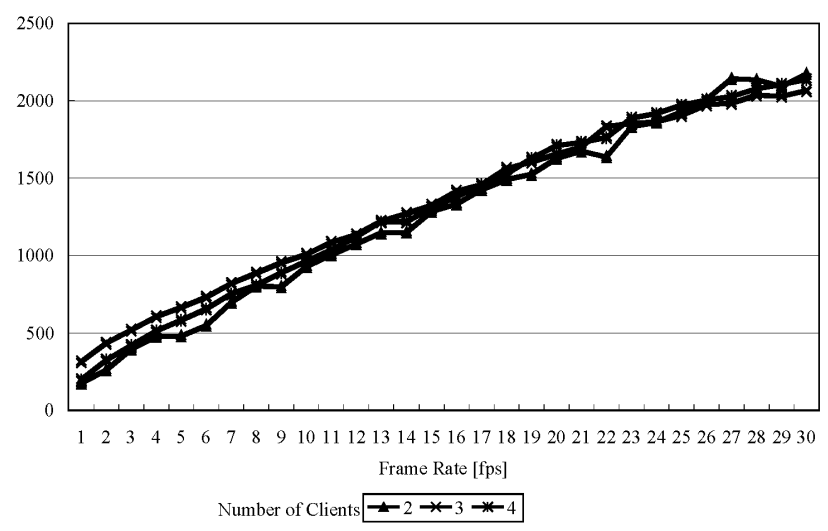

Figure 13 Relation between frame rate and amount of sent data

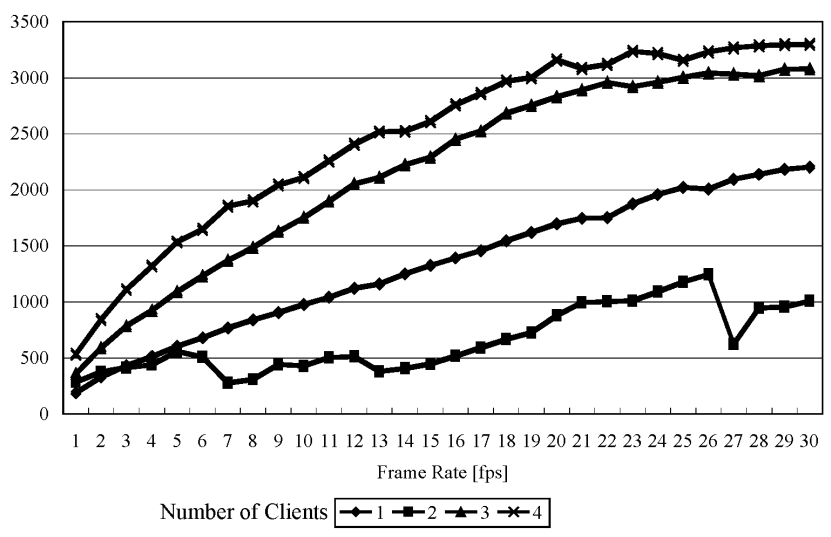

Figure 14 Relation between frame rate and average load

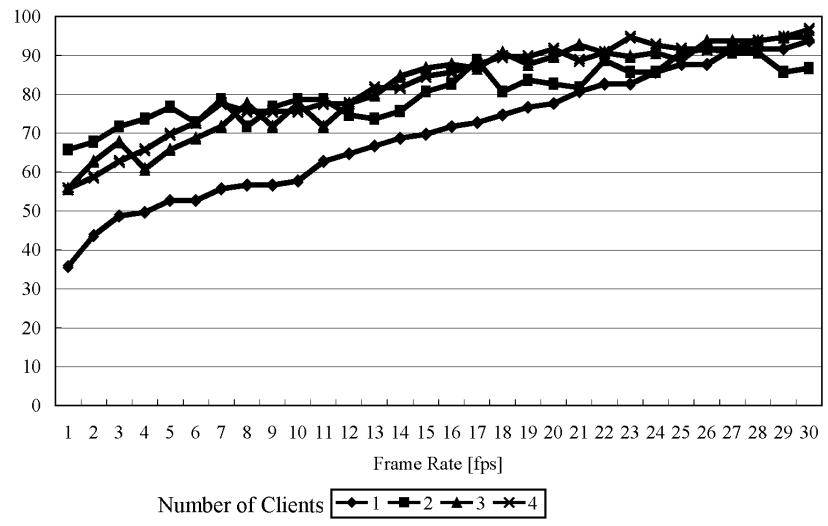

In Figures 15 and 16 are shown the relation between the frame size and throughput at client side and in Figure 17 is shown the relation between the frame size and average load. In this experiment, we use $12 \mathrm{fps}$ as frame rate. We see that the average load 
is affected by the frame size at client side. Also, the average load is different for different number of clients. But, we found that the throughput is not affected by frame size less than $408 \times 544$ pixels. From these results, we conclude that the bandwidth of LAN environment is enough for our system. But, the PCs need more CPU power to send, receive and display the live video when frame rate and frame size are high.

Figure 15 Relation between frame size and amount of received data

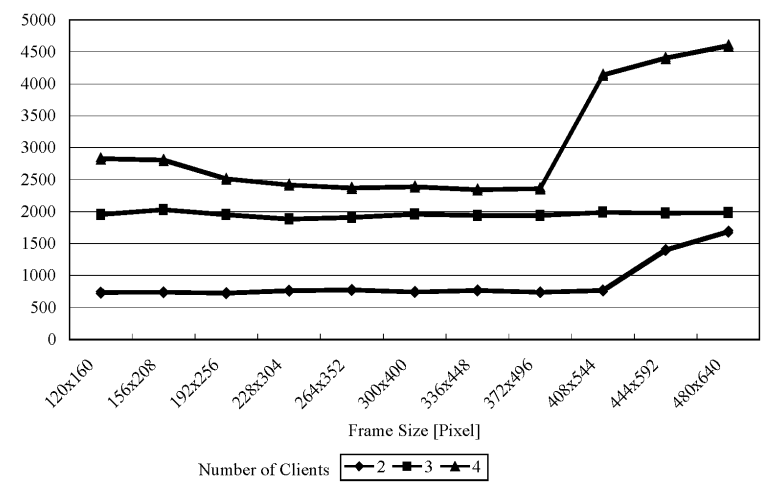

Figure 16 Relation between frame size and amount of sent data

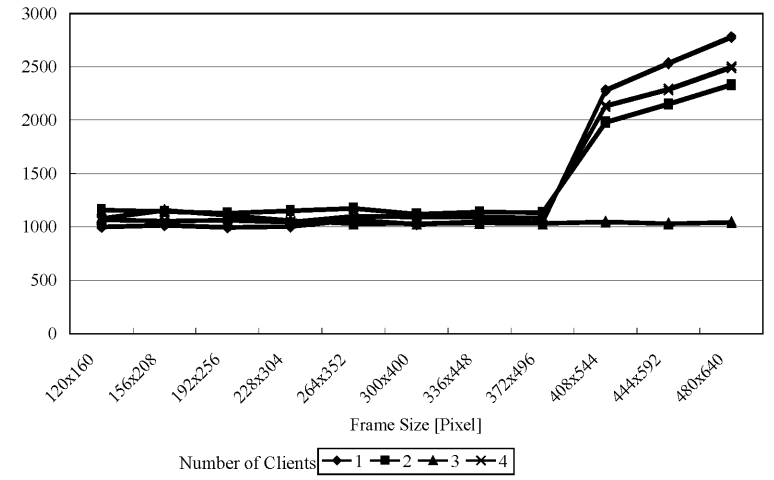

Figure 17 Relation between frame size and average load

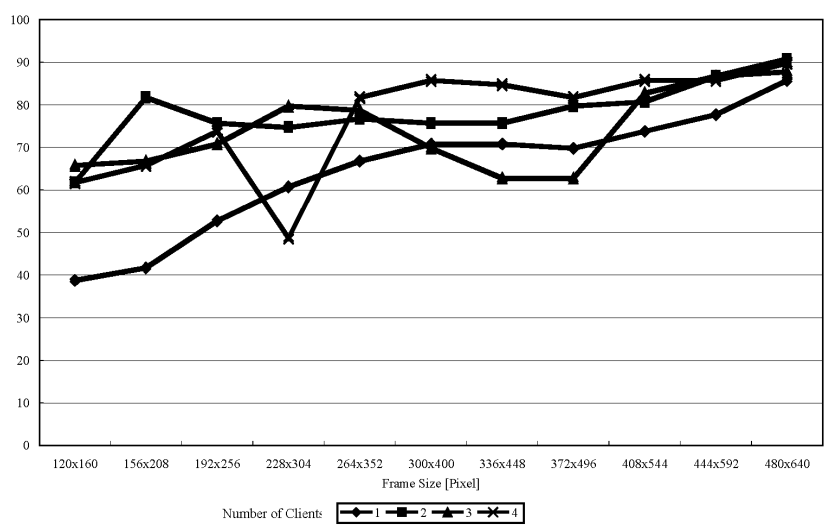




\section{Comparison of proposed and conventional systems}

In Table 2, we compare our proposed system with conventional systems considering network environment, implemented platform, hardware/software, installation and set-up, and communication service.

Some of conventional systems can be used not only in LAN environment/leased line, but also in internet environment. However, these systems do not run in the multi-platform OSs. Using these systems, each user needs to install and set up the special hardware or software. In some of them is needed only the set-up, but each user needs to make installation of special hardware or software. Furthermore, there are few systems that can be used for point-to-point, multi-point-to-multi-point, and broadcast communication.

Our proposed system can be used in real internet environment, and Windows, Macintosh and Linux OSs. To use our system, the user needs only access to the WWW conference server by using WWW browser. After that, the system is installed and set up automatically. Also, the proposed system supports point-to-point, multi-point-to-multi-point and broadcast communication.

Table 2 Comparison of proposed and conventional systems

\begin{tabular}{|c|c|c|c|c|c|}
\hline Systems & $\begin{array}{l}\text { Network } \\
\text { environment }\end{array}$ & $\begin{array}{l}\text { Implementation } \\
\text { platform }\end{array}$ & $\begin{array}{l}\text { Hardware } \\
\text { software }\end{array}$ & $\begin{array}{l}\text { Installation } \\
\text { and set-up }\end{array}$ & $\begin{array}{l}\text { Communication } \\
\text { service }\end{array}$ \\
\hline $\begin{array}{l}\text { Inoue et al. } \\
\text { (1997) }\end{array}$ & $\begin{array}{l}\text { LAN } \\
\text { environment }\end{array}$ & Sun workstation & $\begin{array}{l}\text { Special } \\
\text { software } \\
\text { special } \\
\text { hardware }\end{array}$ & Needed & $\begin{array}{l}\text { Multi-point-to-multi- } \\
\text { point }\end{array}$ \\
\hline $\begin{array}{l}\text { Kawamura } \\
\text { et al. (2003) }\end{array}$ & $\begin{array}{l}\text { LAN } \\
\text { environment } \\
\text { leased line }\end{array}$ & Windows & $\begin{array}{l}\text { Special } \\
\text { software } \\
\text { special } \\
\text { hardware }\end{array}$ & Needed & Point-to-point \\
\hline $\begin{array}{l}\text { Kato } \\
\text { et al. (2003) }\end{array}$ & Internet & Windows & $\begin{array}{l}\text { Special } \\
\text { software }\end{array}$ & Needed & Broadcast \\
\hline Sony (2004) & Internet & Special hardware & $\begin{array}{l}\text { Special } \\
\text { hardware }\end{array}$ & $\begin{array}{l}\text { Need only } \\
\text { set-up }\end{array}$ & $\begin{array}{l}\text { Point-to-point multi- } \\
\text { point-to-multi-point } \\
\text { broadcast }\end{array}$ \\
\hline Netmeeting & Internet & Windows & $\begin{array}{l}\text { Special } \\
\text { software }\end{array}$ & $\begin{array}{l}\text { Need only } \\
\text { set-up }\end{array}$ & Point-to-Point \\
\hline $\begin{array}{l}\text { Proposed } \\
\text { WWW } \\
\text { conference } \\
\text { system }\end{array}$ & Internet & $\begin{array}{l}\text { Windows } \\
\text { Macintosh Linux }\end{array}$ & $\begin{array}{l}\text { WWW } \\
\text { browser }\end{array}$ & Automatically & $\begin{array}{l}\text { Point-to-point multi- } \\
\text { point-to-multi-point } \\
\text { broadcast }\end{array}$ \\
\hline
\end{tabular}

\section{Conclusions}

In this paper, we proposed a WWW conference system. We presented the connection management methods for realising each type of conference. We show the WWW conference operation and implementation. Finally, we discussed the evaluation of our proposed system. From experimental results, we conclude as follows: 
- the WWW conference client can send and receive the live videos for four users in the LAN environment

- the WWW conference clients need more CPU power to send, receive and display the live video

- the WWW conference system can be used in the internet environment.

Now, we are evaluating the proposed system for different kinds of networks and number of hops. In the future, we would like to use the proposed system for mental healthcare education and counselling.

\section{References}

Abiko, T., Iijima, H., Koyama, A., Kamibayashi, N. and Narita, N. (2003) 'Implementation and Verification of Care Communications Service Between Hospitalized Patients and their Families, IPSJ SIG Technical Report DPS, Vol. 114-6, pp.37-43 (in Japanese).

Advanced Solutions (2001) moNet, http://www.asi.co.jp/monet/index.html (in Japanese).

Advanced Solutions (2002) Impression Live, http://www.asi.co.jp/imlive/index.html (in Japanese).

Fuji-shi (2005) Fuji-shi Live Camera, http://www.city.fuji.shizuoka.jp/live/.

Hitachi Hybrid Network (2004) IP Visual Communication System NetCS, http://www.hitachi hybrid.co.jp/business/net/netcs01.html.

Inoue, T., Okada, K. and Matsushita, Y. (1997) 'Spatial design for integration of face-to-face and video meetings: hermes video conferencing system', IEICE, Vol. J80-D-II, No. 9, pp.2482-2492 (in Japanese).

Kato, Y., Jiang, D. and Hakozaki, K. (2003) 'A proposal of a streaming video system in best-effort networks using adaptive qos control rules', IPSJ DPSWS'2003, IPSJ Symposium Series, Vol. 19, pp.7-12 (in Japanese).

Kawamura, N., Maita, Y., Hashimoto, K. and Shibata, Y. (2003) 'Remote medical support system using the transcoding function', IPSJ SIG Technical Report DPS, Vol. 113-5, pp.69-74 (in Japanese).

Kumamoto-shi (2001) Today's Kumamoto Castle, http://www.city.kumamoto.kumamoto.jp/castle Today.html.

Macromedia (2003) Flash Communication Server MX 1.5, http://www.adobe.com/support/ documentation/en/flashcom/.

Macromedia (2004) Flash MX 2004, http://www.adobe.com/support/documentation/en/flash/ documentation-mx.html.

Maeda, K., Aibara, R., Kawamoto, K., Terauchi, M., Kohno, E. and Nishimura, K. (1997) 'Multimedia communication environment for distance learning', IEICE, Vol. J80-B-I, No. 6, pp.348-354 (in Japanese).

Microsoft (2004) Netmeeting, http://www.microsoft.com/windows/netmeeting/.

Miyoshi, K., Okanaga, Y., Kou, S. and Kondo, S. (2000) 'Design, development and experiments of distance learning systems by satellite internet services', IEICE, Vol. J83-D-I, No. 6, pp.644-650 (in Japanese).

Mori, K., Oyabu, Y., Nomura, A. and Oshita, S. (1992) 'Inter-campus tele-education and its evaluation', IEICE, Vol. J75-A, No. 2, pp.244-255 (in Japanese).

NEC Engineering (1996) Remote Conference System, http://www.nec-eng.com/kaigi/index.html (in Japanese).

NTT West (2004) Technical Report, p.12, http://www.ntt-west.co.jp/ipnet/ip/siryou.pdf (in Japanese). 
Polycom (2004) http://www.polycom.com/home.

Sakiyama, T., Ohono, N., Mukunoki, M. and Ikeda, K. (2001) 'Video stream selection according to lecture context in remote lecture', IEICE, Vol. J84-D-II, No. 2, pp.248-257 (in Japanese).

Sapporo-shi (2004) Tokeidai at the Moment, http://web.city.sapporo.jp/livecamera/.

Sony (2004) Video Conference System PCS-1, http://bssc.sel.sony.com/Professional/markets/ videoconferencing/overview.html.

Sugita, K., Uchida, N., Miyakawa, A. and Barolli, L. (2005) 'Implementation of WWW conference system for supporting remote mental health care education', Proc. Seventh International Workshop on Multimedia Network Systems and Applications (MNSA2005), pp.686-692.

The House of Councilors (2005) The House of Councilors Internet TV, http://www.webtv.sangiin. go.jp/webtv/index.php (in Japanese).

The House of Representatives (1999) The House of Representatives Internet TV, http://www. shugiintv.go.jp/top.cfm.

The Ministry of Public Management (2004) Home Affairs, Posts and Telecommunication, http://www.soumu.go.jp/media/index.html.

Visual Nexus (2004) Visual Online Conference System, http://www.visualnexus.com/en/ index.html.

vtel (2004) http://www.vtel.com/.

Wakahara, T. (1998) 'Configuration and Characteristics of distance learning system over atm-pvc network', IEICE, Vol. J81-B-I, No. 8, pp.494-506 (in Japanese).

Yamaguchi, T., Sakano, T., Fujii, T., Ando, Y. and Kitamura, M. (2001) 'Design of medical tele-consultation support system using super high definition imaging system', IEICE, Vol. J84-D-II, No. 6, pp.1203-1212 (in Japanese) 